\title{
Ultra-Performance Liquid Chromatography-Tandem Mass Spectrometry for the Analysis of Complex Compounds in Serum and Its Application in Accurate Detection of Early Arsenic Exposure
}

\author{
Nan Jing, Xinzheng Wang, Xin Yang, Qian Liu, Hongxia Wang, Fangting Dong, Kun He,* \\ and $\mathrm{Na}$ Wang*
}

Cite This: ACS Omega 2021, 6, 28326-28333

Read Online

ABSTRACT: With the acceleration of industrialization, environmental arsenic pollution is threatening human health. However, by the time clinical symptoms appear, arsenic toxicity has usually caused irreversible damage to the body, so it is important to establish a rapid and accurate screening method for early arsenic exposure. In this work, 32 female C57BL/6 mice were exposed to different concentrations of inorganic arsenic in drinking water for a week. By analyzing the changes in serum, more than 20 compounds were detected to increase or decrease with the increase of arsenic intake. The abnormal increase in inosine, xanthine, xanthosine, and hypoxanthine and the abnormal purine pathway were found at the same time. Dimethylarsenic acid, an important inorganic arsenic metabolite in the body, was also found in serum. Combined with statistical analysis, early arsenic exposure can be easily and quickly detected, and the potential health risks of short-term exposure can be revealed simultaneously.

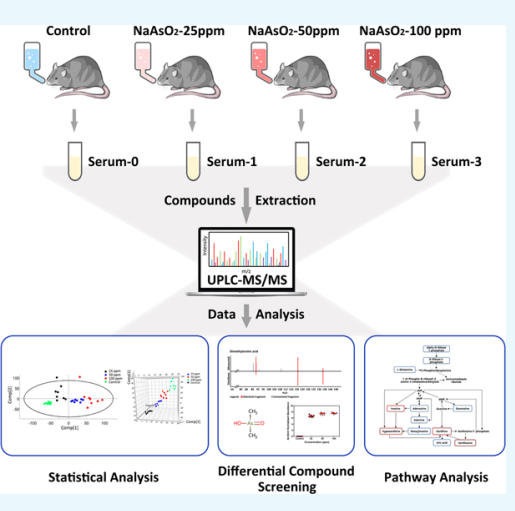

\section{INTRODUCTION}

Arsenic is a naturally occurring element in the earth's crust, which is mostly in the form of trivalent or pentavalent compounds in the natural world. Exposure to arsenic may cause many diseases, such as diabetes, ${ }^{1-3}$ cardiovascular diseases, ${ }^{4-7}$ and kinds of cancers. ${ }^{8-12}$ International Agency for Research on Cancer (IARC) has identified arsenic and its compounds as explicit human carcinogens. ${ }^{13,14}$ Excessive arsenic content in water resources is one of the important ways for human arsenic exposure. With the rapid development of industries, a large amount of high-arsenic wastewater was discharged into rivers and lakes; arsenic contamination in drinking water has been a global health problem for the past few decades. ${ }^{15-18}$ Moreover, arsenic is also emitted into the environment by burning arsenic coal, ${ }^{19,20}$ leading to excessive exposure of arsenic to the inhabitants of relevant areas.

Many research studies have attempted to reveal the toxicity of arsenic to human, especially trivalent inorganic arsenic. Inorganic arsenic and its compounds were generally considered to be more toxic than organic arsenic. ${ }^{21-26}$ Modern studies have shown that exposure to inorganic arsenic could lead to DNA damage ${ }^{27-30}$ and protein denaturation. ${ }^{31-33}$ Although many research studies aimed at revealing the mechanism of arsenic damage to body, early detection of arsenic exposure at low doses was still difficult. When clinical symptoms of arsenic exposure have occurred, the body has usually already suffered some serious damage. Therefore, accurate detection of early exposure to low-concentration inorganic arsenic has great significance for early warning of arsenic damage risk and monitoring of environmental arsenic pollution.

Ultra-performance liquid chromatography-tandem mass spectrometry (UPLC-MS/MS) is a useful method for separation and analysis of complex mixtures, and it is widely used in analysis of complex biological samples such as blood and urine. In this work, UPLC-MS/MS was used to detect changes in serum compounds in mice after short-term arsenic exposure. More than 20 serum compounds were altered and purine pathways were found to be abnormal after arsenic exposure. Although serum arsenic content remains at an extremely low level when the drinking arsenic intake increases, dimethylarsenic acid, an important in vivo metabolite of sodium arsenite, was still detected. Combined with statistical analysis, early arsenic exposure can be easily and quickly detected, and the potential health risks of short-term arsenic exposure can be revealed simultaneously.

\section{RESULTS AND DISCUSSION}

Physiological Status after Arsenic Exposure. After a week of sodium arsenite exposure, mice in the control group

Received: August 18, 2021

Accepted: September 22, 2021

Published: October 12, 2021 
Table 1. Differential Compounds in Serum after Arsenic Exposure

\begin{tabular}{|c|c|c|c|c|c|c|}
\hline formula & compound name & change & $\begin{array}{l}\max \text { fold } \\
\text { change }\end{array}$ & score & $\begin{array}{c}\text { Anova } \\
(p)\end{array}$ & $q$ value \\
\hline $\mathrm{C}_{15} \mathrm{H}_{29} \mathrm{NO}_{4}$ & $( \pm)$-octanoylcarnitine & $\downarrow$ & 4.324 & 56 & 0.003 & 0.008 \\
\hline $\mathrm{C}_{15} \mathrm{H}_{15} \mathrm{NO}_{8}$ & 3-indole carboxylic acid glucuronide & $\uparrow$ & 15.057 & 53.9 & 0.001 & $\begin{array}{r}3.77 \times \\
10^{-4}\end{array}$ \\
\hline $\mathrm{C}_{21} \mathrm{H}_{32} \mathrm{O}_{2}$ & 5-alpha-pregnane-3,20-dione & $\downarrow$ & 9.282 & 50.2 & $\begin{array}{r}3.65 \times \\
10^{-6}\end{array}$ & $\begin{array}{r}3.50 \times \\
10^{-5}\end{array}$ \\
\hline $\mathrm{C}_{27} \mathrm{H}_{44} \mathrm{O}_{3}$ & 23S,25-dihydroxyvitamin D3 & $\downarrow$ & 5.113 & 53 & 0.001 & $\begin{array}{r}2.38 \times \\
10^{-3}\end{array}$ \\
\hline $\mathrm{C}_{21} \mathrm{H}_{30} \mathrm{O}_{5}$ & cortisol & $\downarrow$ & 5.832 & 50.6 & 0.001 & $\begin{array}{r}4.60 \times \\
10^{-3}\end{array}$ \\
\hline $\mathrm{C}_{15} \mathrm{H}_{15} \mathrm{NO}_{8}$ & 2,8-dihydroxyquinoline-beta-D-glucuronide & $\uparrow$ & 10.355 & 54.3 & $\begin{array}{r}7.89 \times \\
10^{-5}\end{array}$ & $\begin{array}{r}4.98 \times \\
10^{-4}\end{array}$ \\
\hline $\mathrm{C}_{14} \mathrm{H}_{15} \mathrm{NO}_{8}$ & dihyroxy- $1 H$-indole glucuronide I & $\uparrow$ & 4.260 & 56.1 & $\begin{array}{r}8.98 \times \\
10^{-5}\end{array}$ & $\begin{array}{r}2.69 \times \\
10^{-4}\end{array}$ \\
\hline $\mathrm{C}_{12} \mathrm{H}_{14} \mathrm{O}_{7}$ & phenol glucuronide & $\uparrow$ & 3.497 & 56.7 & $\begin{array}{r}8.29 \times \\
10^{-5}\end{array}$ & $\begin{array}{r}2.53 \times \\
10^{-4}\end{array}$ \\
\hline $\mathrm{C}_{15} \mathrm{H}_{17} \mathrm{NO}_{8}$ & 6-hydroxy-5-methoxyindole glucuronide & $\uparrow$ & 15.429 & 55.9 & $\begin{array}{r}1.70 \times \\
10^{-4}\end{array}$ & $\begin{array}{r}4.53 \times \\
10^{-4}\end{array}$ \\
\hline $\mathrm{C}_{15} \mathrm{H}_{15} \mathrm{NO}_{8}$ & 3,4,5-trihydroxy-6-(1H-indole-3-carbonyloxy)oxane-2-carboxylic acid & $\uparrow$ & 9.610 & 57.5 & $\begin{array}{r}2.24 \times \\
10^{-4}\end{array}$ & $\begin{array}{c}5.66 \times \\
10^{-4}\end{array}$ \\
\hline $\mathrm{C}_{12} \mathrm{H}_{16} \mathrm{O}_{12}$ & $\alpha$-L-threo-4-hex-4-enopyranuronosyl-D-galacturonic acid & $\uparrow$ & 7.539 & 54.8 & 0.001 & $\begin{array}{c}2.05 \times \\
10^{-4}\end{array}$ \\
\hline $\mathrm{C}_{10} \mathrm{H}_{12} \mathrm{~N}_{4} \mathrm{O}_{6}$ & xanthosine & $\uparrow$ & 3.671 & 57.8 & $\begin{array}{r}9.09 \times \\
10^{-5}\end{array}$ & $\begin{array}{r}4.04 \times \\
10^{-5}\end{array}$ \\
\hline $\mathrm{C}_{10} \mathrm{H}_{12} \mathrm{~N}_{4} \mathrm{O}_{5}$ & inosine & $\uparrow$ & 170.765 & 57 & $\begin{array}{r}5.30 \times \\
10^{-5}\end{array}$ & $\begin{array}{r}5.85 \times \\
10^{-5}\end{array}$ \\
\hline $\mathrm{C}_{10} \mathrm{H}_{12} \mathrm{~N}_{4} \mathrm{O}_{4}$ & deoxyinosine & $\uparrow$ & 9.678 & 52.9 & $\begin{array}{r}2.41 \times \\
10^{-3}\end{array}$ & $\begin{array}{c}5.54 \times \\
10^{-4}\end{array}$ \\
\hline $\mathrm{C}_{5} \mathrm{H}_{4} \mathrm{~N}_{4} \mathrm{O}$ & hypoxanthine & $\uparrow$ & 49.236 & 57.8 & $\begin{array}{r}4.06 \times \\
10^{-5}\end{array}$ & $\begin{array}{r}2.14 \times \\
10^{-4}\end{array}$ \\
\hline $\mathrm{C}_{5} \mathrm{H}_{4} \mathrm{~N}_{4} \mathrm{O}_{2}$ & xanthine & $\uparrow$ & 614.780 & 56.6 & $\begin{array}{r}1.60 \times \\
10^{-8}\end{array}$ & $\begin{array}{r}1.10 \times \\
10^{-6}\end{array}$ \\
\hline $\mathrm{C}_{5} \mathrm{H}_{11} \mathrm{NO}_{3} \mathrm{~S}$ & L-methionine $S$-oxide & $\uparrow$ & 9.094 & 54.3 & 0 & 0 \\
\hline $\mathrm{C}_{8} \mathrm{H}_{8} \mathrm{O}_{4} \mathrm{~S}$ & 4-vinylphenol sulfate & $\downarrow$ & 4.797 & 52.4 & $\begin{array}{r}3.04 \times \\
10^{-11}\end{array}$ & $\begin{array}{c}3.53 \times \\
10^{-10}\end{array}$ \\
\hline $\mathrm{C}_{6} \mathrm{H}_{8} \mathrm{~N}_{2} \mathrm{O}_{2}$ & pi-methylimidazoleacetic acid & $\uparrow$ & 3.975 & 51 & 0.009 & $\begin{array}{r}3.92 \times \\
10^{-3}\end{array}$ \\
\hline $\mathrm{C}_{6} \mathrm{H}_{6} \mathrm{~N}_{2} \mathrm{O}_{2}$ & urocanic acid & $\uparrow$ & 3.103 & 57.7 & 0.001 & $\begin{array}{r}4.69 \times \\
10^{-4}\end{array}$ \\
\hline $\mathrm{C}_{21} \mathrm{H}_{22} \mathrm{O}_{13} \mathrm{~S}$ & $\begin{array}{l}\text { (\{6-[5,7-dihydroxy-2-(4-hydroxyphenyl)-4-oxo-3,4-dihydro-2H-1-benzopyran-8-yl]- } \\
\text { 3,4,5-trihydroxyoxan-2-yl }\} \text { methoxy)sulfonic acid }\end{array}$ & $\uparrow$ & 11.536 & 51 & $\begin{array}{r}7.84 \times \\
10^{-8}\end{array}$ & $\begin{array}{r}9.70 \times \\
10^{-7}\end{array}$ \\
\hline $\mathrm{C}_{12} \mathrm{H}_{14} \mathrm{O}_{8}$ & uralenneoside & $\uparrow$ & 3.955 & 54 & $\begin{array}{r}1.77 \times \\
10^{-4}\end{array}$ & $\begin{array}{r}4.68 \times \\
10^{-4}\end{array}$ \\
\hline $\mathrm{C}_{21} \mathrm{H}_{18} \mathrm{O}_{10}$ & daidzein 7-O-glucuronide & $\uparrow$ & 8.908 & 54.1 & $\begin{array}{r}6.82 \times \\
10^{-6}\end{array}$ & $\begin{array}{r}3.39 \times \\
10^{-5}\end{array}$ \\
\hline $\mathrm{C}_{2} \mathrm{H}_{7} \mathrm{AsO}_{2}$ & dimethylarsenic & $\uparrow$ & infinity & 54.8 & 0 & 0 \\
\hline $\mathrm{C}_{9} \mathrm{H}_{13} \mathrm{~N}_{5} \mathrm{O}_{3}$ & 1-hydroxy-2-oxopropyl tetrahydropterin & $\downarrow$ & 123.289 & 53.1 & $\begin{array}{r}5.24 \times \\
10^{-8}\end{array}$ & $\begin{array}{r}2.05 \times \\
10^{-7}\end{array}$ \\
\hline $\mathrm{C}_{21} \mathrm{H}_{30} \mathrm{O}_{4}$ & $7^{\prime}$-carboxy-alpha-tocotrienol & $\downarrow$ & 52.270 & 50.9 & $\begin{array}{r}7.28 \times \\
10^{-6}\end{array}$ & $\begin{array}{r}6.59 \times \\
10^{-5}\end{array}$ \\
\hline $\mathrm{C}_{9} \mathrm{H}_{10} \mathrm{O}_{7} \mathrm{~S}$ & 3-(3,5-dihydroxyphenyl)-1-propanoic acid sulfate & $\uparrow$ & 5.857 & 54.4 & $\begin{array}{r}1.28 \times \\
10^{-9}\end{array}$ & $\begin{array}{r}4.03 \times \\
10^{-8}\end{array}$ \\
\hline $\mathrm{C}_{21} \mathrm{H}_{18} \mathrm{O}_{11}$ & baicalin & $\uparrow$ & 9.076 & 53.3 & $\begin{array}{r}7.52 \times \\
10^{-8}\end{array}$ & $\begin{array}{r}9.43 \times \\
10^{-7}\end{array}$ \\
\hline
\end{tabular}

and all experimental groups showed the same physiological status and behavior. The mice in three experimental groups showed no appearance changes such as hair loss, and no abnormal conditions such as convulsion, lethargy, and motor behavior changes. Moreover, the addition of different concentrations of arsenic did not change the drinking behavior of the mice; all mice in experimental and control groups drank roughly the same amount of water. Therefore, short-term exposure to a low concentration of arsenic generally does not show obvious discomfort symptoms, resulting in the difficulty of early detection of arsenic exposure.
Arsenic Exposure Perturbed Serum Components. UPLC-MS/MS-based arsenic exposure groups and control group samples, in total, revealed more than 10,000 features, which were contributed by a large number of complex compounds in the serum. After a series of screening, 301 different compounds were identified in serum (the corresponding compound names, molecular formulas, and other information are shown in Table S1, in the Supporting Information). Twenty-eight compounds showed significant concentration changes (increase or decrease) with the increase of arsenic exposure concentration (Table 1), which were considered as potential signals to reveal the harm of short-term 
arsenic intake. Significantly, although the arsenic concentration in serum was extremely low (lower than $0.6 \mathrm{ppm}$, Table 2),

Table 2. Total Arsenic Concentration in Serum of Different Groups

$\begin{array}{cc}\text { initial arsenic concentration in water }(\mathrm{ppm}) & \text { total arsenic in serum }(\mathrm{ppb}) \\ 0(\text { control }) & 5.047 \pm 0.375 \\ 25 & 122.6 \pm 5.681 \\ 50 & 176.6 \pm 11.67 \\ 100 & 540.6 \pm 23.76\end{array}$

dimethylarsenic acid, which stemmed from sodium arsenite metabolism in the body, was still found in serum, and its concentration significantly increased with the growth of arsenic exposure (Figure 4).

The Principle of Statistical Analysis for UPLC-MS/MS

Data. Serum contains a large number of small molecule compounds, which generate huge mass spectral data with useless noise. Thus, a big challenge in analysis of a group mass spectral data is how to effectively extract information from this big data set. UPLC-MS/MS results of serum samples can be viewed as a matrix, which contain a large number of observational variables, compound information, and the corresponding strength of their signals (Figure 1). The

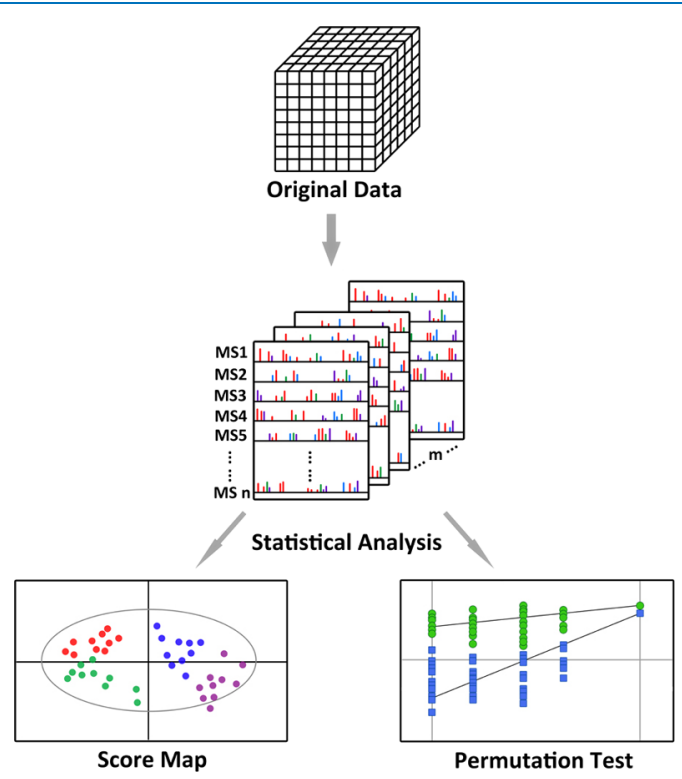

Figure 1. Multivariate statistical analysis for UPLC-MS/MS data.

purpose of multivariate statistical analysis is to reduce the dimensionality of high-dimensional data and display maximum information of the original data with the least number of variables. Meanwhile, multivariate statistical analysis can eliminate the noise and extract useful information from the original data efficiently and accurately.

PCA is probably the most widespread multivariate chemometric technique, and it could transform a large number of related variables into a group of orthogonal variables that best represent data characteristics through linear transformation. Using these orthogonal variables to describe the sample could reduce the dimension of original data and at the same time, remove useless noise. PCA is an unsupervised analysis mode, and the grouping of each sample is unknown during calculations. PCA can clearly display the repeatability within groups and the differences between groups, evaluate the repeatability of data, and find out the possible outliers.

However, due to the complexity of the serum chemical environment, unsupervised analysis is sometimes not good at distinguishing subtle differences between samples. OPLS-DA is a supervised analysis mode; the grouping relationship of samples is known during data analysis. In this way, the characteristic variables of each group can be better selected and distinguished, and the relationship between samples can be determined. Partial least-squares discriminant analysis (PLSDA) used a partial least-squares regression method to reduce the dimension of the data and established a regression model to conduct discriminant analysis on the regression results. OPLS-DA is the correction of orthogonal transformation based on PLS-DA, which can filter out the noise unrelated to the classification information and improve the analytical ability and effectiveness of the model.

Score Plot and Permutation Test. The score is an important parameter in PCA and OPLS-DA analysis results. The score plot can clearly describe the distance between different samples and can be used to distinguish the similarity or difference of samples. In general, the closer the distance between the observed variables is, the higher similarities of samples are. On the contrary, the further the distance between the observed variables, the lower similarities of samples are.

A permutation test is a statistical inference method based on a large number of calculations and uses the complete (or random) arrangement of sample data. The permutation test obtains a statistical result by iterating on the predicted variables according to the known measured data variables. The reliability and overfitting degree of the model were represented by examining the $y$-intercept of the fitting line composed of the corresponding $R^{2}$ and $Q^{2}$ calculated values of all samples. The criteria for model validity are as follows: (1) all $Q^{2}$-values and $R^{2}$-values to the left are lower than the original points to the right; (2) the regression line of the $Q^{2}$ points intersects the vertical axis (on the left) at, or below zero.

Statistical Analysis for Serum Components. All MS/ MS data of the identified compounds were sent to SIMCA 14.1 for statistical analysis. Figure $2 \mathrm{~A}$ shows the score plot of PCA for all control and experimental groups after arsenic exposure. In score plots, each dot represents a serum sample of mice. Although most compound concentrations in serum do not have a significant change after arsenic exposure, PCA could well distinguish the control group from all experimental groups. Under low concentration and short exposure conditions (25 ppm, 1 week), the PCA method was still able to distinguish arsenic exposed mice from normal mice. However, when arsenic concentrations increased above 50 ppm, the unsupervised PCA method was unable to effectively distinguish between the two high-dose groups (50 ppm group and 100 ppm group). In a 3D score plot (Figure 2B), PCA still had difficulty in identifying the two high-dose groups. That is because the significant changes in serum compounds were few and a large number of compounds were not significantly changed. The large number of non-differential compounds caused the two high-dose groups (50 ppm and $100 \mathrm{ppm}$ ) to not be effectively distinguished by PCA.

To solve the problems in PCA, OPLS-DA was used for further difference identification. As a supervised analysis mode, OPLS-DA could better determine the relationship between samples during data analysis. In Figure 2C,D, the score plots of OPLS-DA clearly display that the three arsenic exposure 

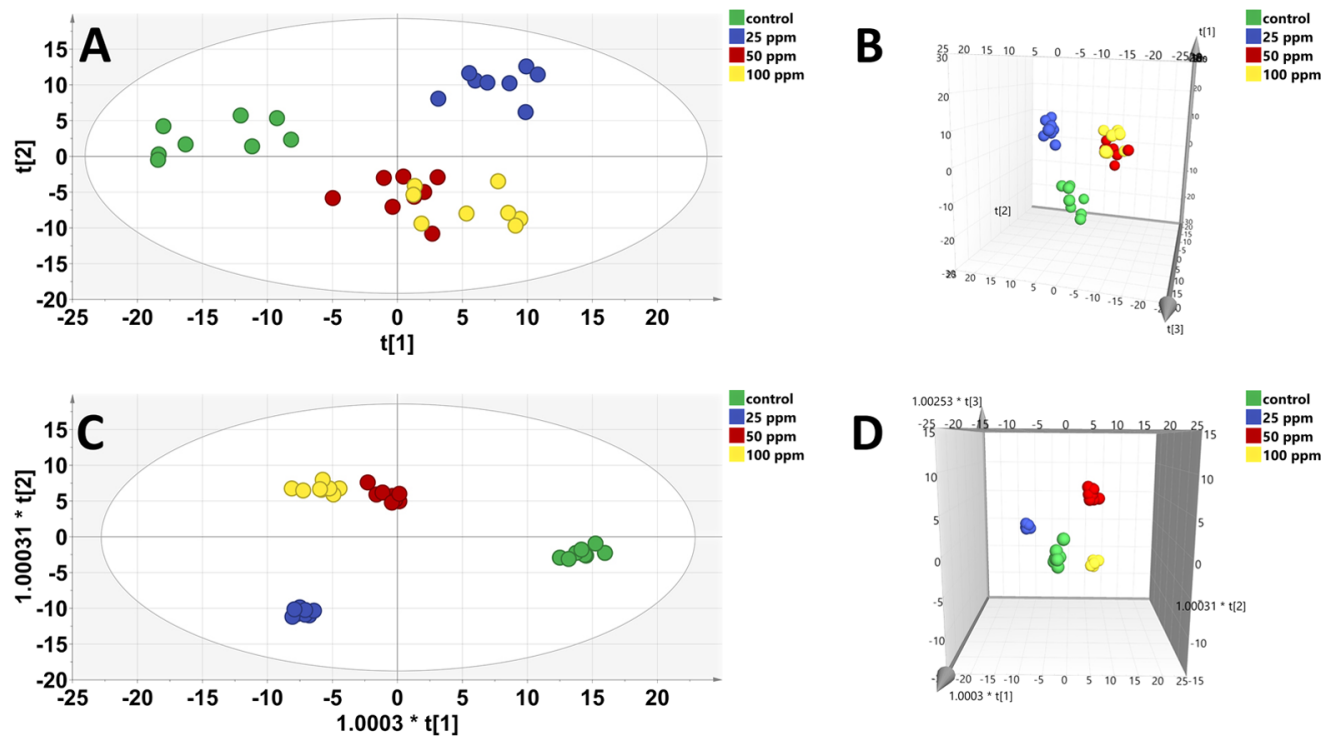

Figure 2. Results of statistical analysis. (A) PCA score plot in a 2D plane, (B) the PCA score plot in a 3D space, (C) OPLS-DA score plot in a 2D plane, and (D) the OPLS-DA score plot in a 3D space.
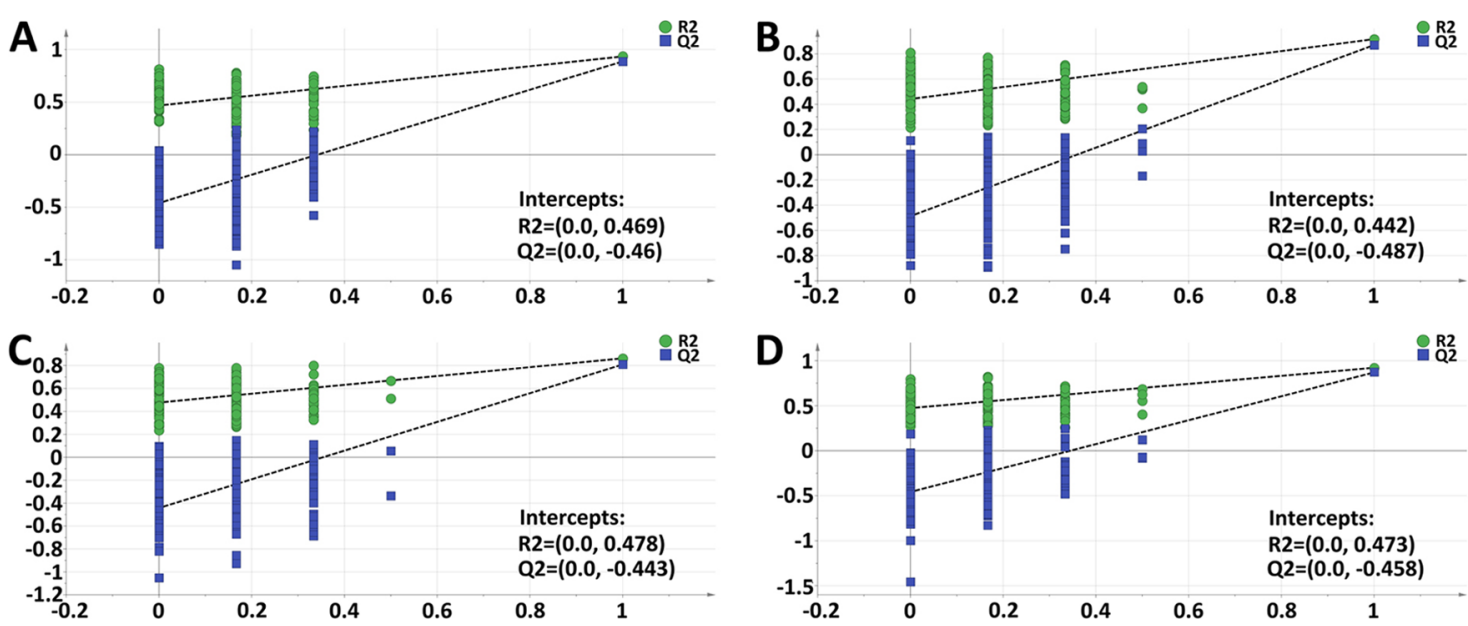

Figure 3. Permutation test of all OPLS-DA results: (A) control group, (B) 25 ppm group, (C) 50 ppm group, and (D) the 100 ppm group.

groups and one control group can be effectively distinguished in both the 2D plane and 3D space. The permutation test was then used to examine the reliability of the OPLS-DA regression model, and the permutation number of each variable was 200 times. For every group, the $y$-intercepts of the fitting lines of $R^{2}$ and $Q^{2}$ are significantly lower than the values of $R^{2}$ and $Q^{2}$ under the corresponding principal component (the high point on the right of the line, Figure 3). The $y$-intercepts of $R^{2}$-point and $Q^{2}$-point regression lines for each group were lower than 0.5 and -0.4 , respectively. The results of the permutation test confirm the validity of the OPLS-DA model.

Combined with subsequent analysis of the pathway and the discovery of arsenic methylation products in serum, the relevant methods can be used to screen the risk of early lowconcentration arsenic exposure.

Arsenic Residue in the Serum. In order to investigate the change of arsenic concentration in serum, ICP-MS was used to detect the total arsenic content in serum of each mouse in the first, and the results are displayed in Table 2 . The results of the control group showed that the total arsenic concentration in the blank serum samples was less than $6 \mathrm{ppb}$. After arsenic ingestion in drinking water, the total arsenic content in serum changed obviously. All three experimental groups showed significant differences compared with the control group $(P<$ $0.0001)$. However, although the serum arsenic concentration of the high-dose group was 100 times higher than that of the control group, the total serum arsenic level was still much lower than 1 ppm. As body metabolism makes the blood chemical environment relatively stable, arsenic is almost never retained in serum. Thus, if the sensitivity of the instrument is not high enough or the control sample is lacking, arsenic exposure risks can be difficult to detect only by routine metal testing.

Dimethylarsenic Acid in Serum. Current mainstream studies believe that inorganic arsenic is excreted from the body after ingestion through a series of methylation processes and almost does not persist in the blood. In our work, ICP-MS results also showed a low level of the total arsenic concentration in serum after drinking intake (Table 2). However, after the UPLC-MS/MS test, dimethylarsenic acid was detected in serum samples of all arsenic exposure groups (Figure 4), and its content increased with the increase of arsenic concentration in drinking water. Dimethylarsenic acid is an inorganic arsenic metabolite that is generally considered 
A Dimethylarsinic acid

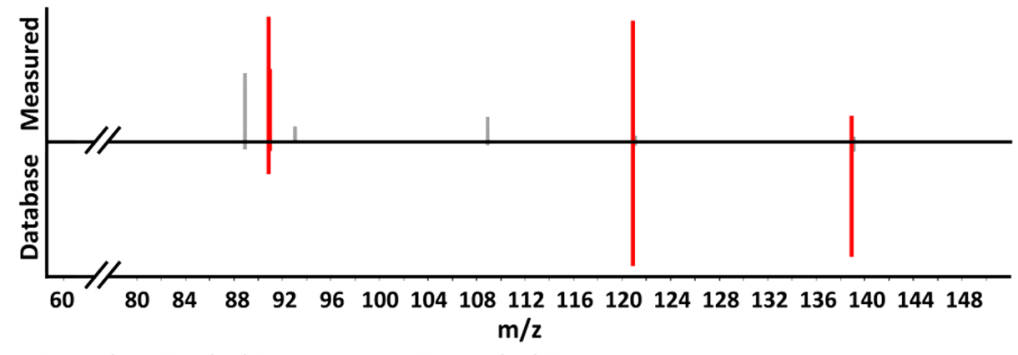

Legend: Matched Fragment

Unmatched Fragment

B

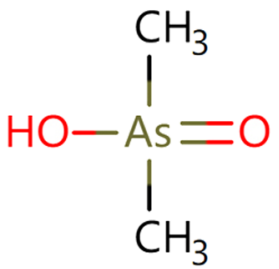

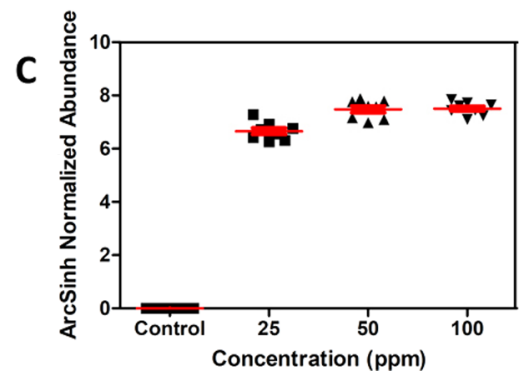

Figure 4. Dimethylarsenic acid in serum; (A) the detected MS spectrum of dimethylarsenic acid (matched with the METLIN database), (B) the structural formula of dimethylarsenic acid, (C) changes in serum dimethylarsenic acid content after different concentrations of arsenic intake.

to be excreted in urine and feces but not retained in the body. ${ }^{34}$ By high-precision mass spectrometry, ultralow concentration compounds can be captured from a complex serum environment.

Arsenic Exposure Affects Purine Metabolism. To determine the health effects of arsenic exposure in mice, the information of all altered compounds was upload to MetaboAnalyst (https://www.metaboanalyst.ca/) for further pathway analysis, and an abnormal purine pathway was found. Eleven identified compounds were located in the middle and downstream of the purine pathway (Figure 5). Inosine, xanthine, xanthosine, and hypoxanthine were the compounds that showed a significant upward trend with the increase of arsenic intake (Figures 6 and 7). Meanwhile, these four compounds were accurately identified by MS/MS experiments of standard chemicals, and the corresponding results are shown in the Supporting Information (Figure S2). Although the mice showed no obvious physiological changes and behavioral abnormalities after 1 week of arsenic exposure, the disorder of purine metabolism is an important warning to the potential harm of short-term inorganic arsenic exposure. In the body, purine metabolism is related to a variety of cell functions, energy conservation and transport, formation of coenzymes and of active intermediates of phospholipids, and carbohydrate metabolism. ${ }^{35}$ Thus, any system may be affected when purine metabolism disorders are present. There are many diseases that can affect purine metabolism, and the possibility of arsenic exposure should be guarded when no abnormality is found in traditional disease tests.

\section{CONCLUSIONS}

In this work, 32 female mice were exposed to different concentrations of inorganic arsenic in drinking water for a week. UPLC-MS/MS was used to detect the changes of compounds in serum after arsenic exposure. The concentrations of inosine, xanthine, xanthosine, and hypoxanthine in serum were detected to increase with the increase of arsenic

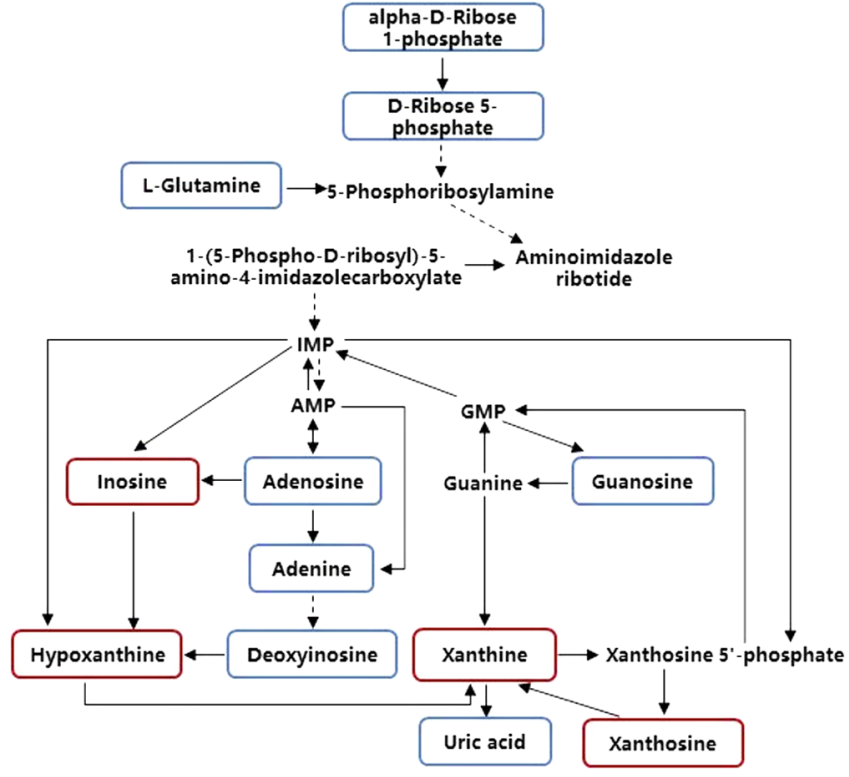

Figure 5. Diagram of the purine pathway. The red box indicates that the content of identified compounds increases with the increase of arsenic exposure concentration; the blue box indicates that the content of identified compounds does not change significantly with the increase of arsenic exposure concentration; those with no box represent compounds not detected by UPLC-MS/MS in serum.

concentration in drinking water, indicating abnormal purine metabolism. Meanwhile, although the total arsenic concentration in serum was extremely low, dimethylarsenic acid, a methylation intermediate metabolized by inorganic arsenic in vivo, was detected in serum. By PCA and OPLS-DA methods, mice in different arsenic exposure groups and the control group could be clearly distinguished. In addition, statistical analysis was able to distinguish arsenic-exposed mice from normal mice at low concentrations of arsenic for short periods of time ( 25 ppm, 1 week). The relevant studies of this work are 
A
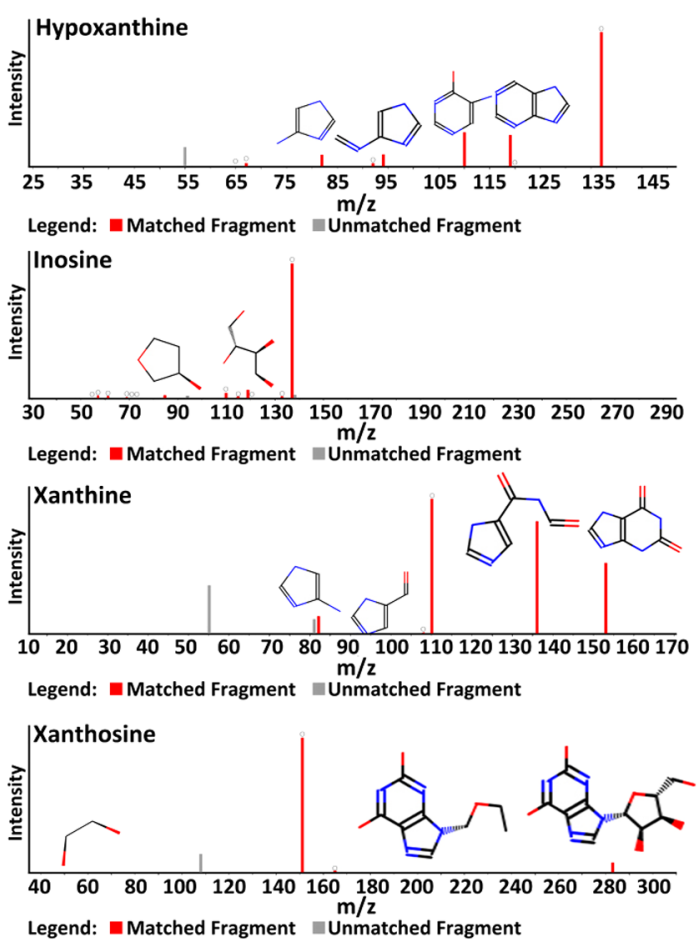

B

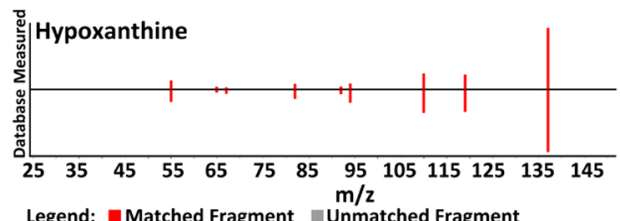<smiles>Oc1ncnc2nc[nH]c12</smiles>

Legend: $\square$ Matched Fragment $\square$ Unmatched Fragment

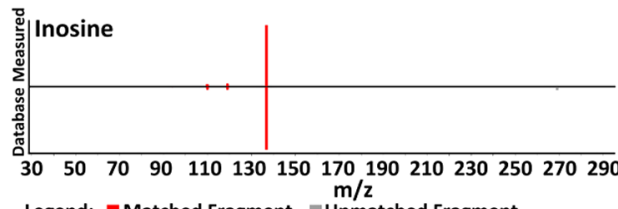

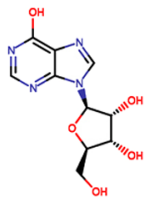

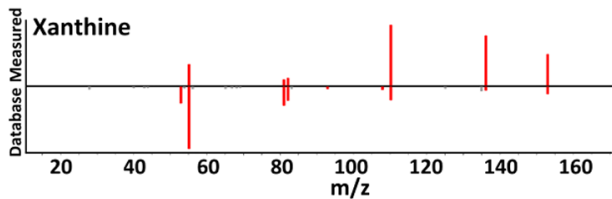<smiles>O=c1[nH]c(=O)c2[nH]cnc2[nH]1</smiles>

Legend: $\square$ Matched Fragment $\square$ Unmatched Fragment

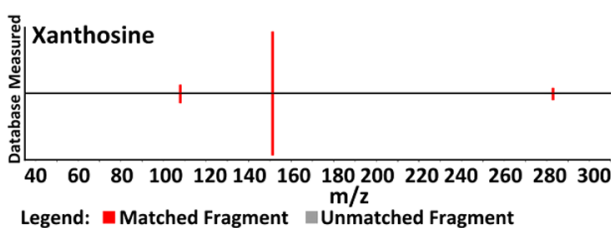

Figure 6. MS spectra and the corresponding structural formulas of inosine, xanthine, xanthosine, and hypoxanthine, (A) matched with the HMDB database and (B) matched with the METLIN database.
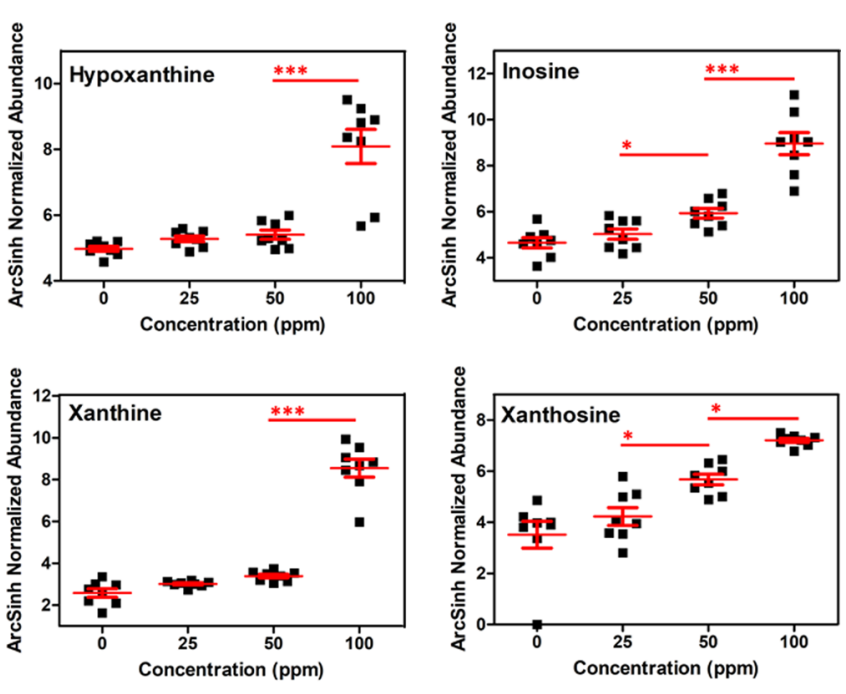

$* \mathrm{P}<0.05 ; * * * \mathrm{P}<0.001$

Figure 7. Contents of inosine, xanthine, xanthosine, and hypoxanthine in serum increased with the increase of arsenic intake.

helpful for accurate and rapid detection of arsenic exposure in the early stage and can reveal the potential health risks of arsenic exposure in the short term.

\section{MATERIALS AND METHODS}

Instruments, Materials, and Reagents. An LC-30 AD ultrahigh-performance liquid chromatography system (Shimadzu, Japan) coupled with a TripleTOF 6600 hybrid Q-TOF mass spectrometer (AB SCIEX, USA) was used to separate and detect serum samples. A Thermo iCAP $Q$ inductively coupled plasma mass spectrometry system (ICP-MS, Thermo
Fisher, USA) was used to investigate the total arsenic concentration in serum.

Progenesis QI (Waters, USA) was used for MS data analysis and serum compound identification. SIMCA 14.1 (MKS UMETRICS) was used for the corresponding statistical analysis.

Sodium arsenite $\left(\mathrm{NaAsO}_{2}\right)$ was purchased from Aladdin Biochemical Technology Co., Ltd. (Shanghai, China). Methanol, acetonitrile, formic acid, and nitric acid were purchased from Thermo Fisher Scientific Inc. $\mathrm{NaAsO}_{2}$ was of analytical grade and the remaining chemicals were of mass pure grade, and all chemicals were used without further purification.

Animal Experiments. Previous studies have shown that female mice are more sensitive to the effects of inorganic arsenic than males. ${ }^{34,36}$ In this work, 32 specific-pathogen-free grade (SPF) C57BL/6 female mice (18-22 g weight) were purchased from Charles River Experimental Animal Technology Co., Ltd (Beijing, China). These mice were randomly assigned to three arsenic-treated groups and one control group, and each group has eight mice. All mice were housed in polycarbonate cages on dry corncob bedding (4 mice/cage) under a barrier condition with a stable environment $\left(22^{\circ} \mathrm{C}\right.$, $40-70 \%$ humidity, and a $12 \mathrm{~h}$ light/dark cycle), and fed a standard pelleted rodent diet. After a week of acclimatization, the arsenic-treated groups were exposed to 25, 50, and 100 $\mathrm{ppm}$ arsenic in drinking water for a week, respectively, and the control group was fed with purified water. After a week of arsenic exposure, all mice were anesthetized with isoflurane, and the serum was sampled from mice eyes. The serum samples were stored at $-80{ }^{\circ} \mathrm{C}$ for subsequent testing. All animal experiments in this work were approved by IACUC of the National Center for Biomedical Analysis; the permit number was IACUC-DWZX-2019-520. 
Serum Preparation. Briefly, $400 \mu \mathrm{L}$ of methanol/ acetonitrile solution $(1: 1, \mathrm{v}: \mathrm{v})$ was added into $100 \mu \mathrm{L}$ of serum to remove proteins. The mixture was vortexed for $30 \mathrm{~s}$ and incubated at $-20{ }^{\circ} \mathrm{C}$ for $1 \mathrm{~h}$ and then centrifuged for 15 min at $15,000 \mathrm{rpm}$ and $4{ }^{\circ} \mathrm{C}$. The supernatant was collected and transferred to new centrifuge tubes and dried in a SpeedVac (FreeZone, Labconco, USA) at $4{ }^{\circ} \mathrm{C}$. The dry samples were resuspended in $50 \%$ cold methanol solution that contains $1 \%$ o formic acid for subsequent analysis.

ICP-MS Analysis. All serum samples were diluted 30 times by a gravimetric method using $2 \%$ nitric acid, and the total arsenic content of each sample was measured by ICP-MS. The power of ICP-MS was $1500 \mathrm{~W}$, and the pump speed was 50 $\mathrm{rpm}$. The auxiliary gas flow and atomized gas flow were $1.5 \mathrm{~L} /$ min, and the cooling air flow was $12 \mathrm{~L} / \mathrm{min}$.

UPLC-MS/MS Analysis. All serum samples were tested by an LC-30 $\mathrm{AD}$ ultrahigh-performance liquid chromatography system coupled with a hybrid Q-TOF mass spectrometer in both positive and negative ion modes. In order to increase the compounds' coverage, both a $2.1 \times 100 \mathrm{~mm}$ ACQUITY 1.8 $\mu \mathrm{m}$ HSS T3 column (Waters Corporation, Milford, USA, Ireland) and a $2.1 \times 100 \mathrm{~mm}$ ACQUITY $1.7 \mu \mathrm{m} \mathrm{BEH}$ amide column (Waters Corporation, Milford, USA) were used to perform the compounds' separation, respectively. For the UPLC separation (T3 column), the mobile phases were (A) water with $0.1 \%$ formic acid (FA) and (B) acetonitrile with $0.1 \% \mathrm{FA}$. The gradient was set as follows: $0-1.5 \mathrm{~min}, 1 \% \mathrm{~B}$; 1.5-13.0 min, 1-99\% B; $13.0-16.5 \mathrm{~min}, 99 \% \mathrm{~B} ; 16.6-20.0$ min, 1\% B. For the hydrophilic interaction chromatography (HILIC) separation (BEH amide column), the mobile phases were (C) $10 \%$ water/acetonitrile with $10 \mathrm{mM}$ ammonium acetate and $0.1 \% \mathrm{FA}$ and (D) water with $10 \mathrm{mM}$ ammonium acetate and $0.1 \% \mathrm{FA}$. The gradient was set as follows: $0-1.0$ $\min , 5 \% \mathrm{D} ; 1.0-12.0 \mathrm{~min}, 5-55 \% \mathrm{D} ; 12.1-15.0 \mathrm{~min}, 55 \% \mathrm{D}$; 15.1-20.0 $\mathrm{min}, 5 \% \mathrm{D}$. The flow rate was $0.3 \mathrm{~mL} / \mathrm{min}$ and sample injection volumes were $3 \mu \mathrm{L}$. The temperatures of the column and sample chamber were, respectively, maintained at 40 and $10{ }^{\circ} \mathrm{C}$ in both positive and negative ion modes. Calibration solution was inserted every six samples during the test to ensure the accurate analysis of samples (the related experimental methods and results are provided in the Supporting Information).

A TripleTOF 6600 mass spectrometer was operated in datadependent analysis (DDA) mode in both positive and negative ion modes. The $\mathrm{m} / z$ scan range of the precursor ion in fullscan mode was set as 50-1250 Da. For the fragment ion, the $\mathrm{m} / z$ scan range was set as $50-1250 \mathrm{Da}$. Accumulation times of MS1 and MS2 were 150 and $30 \mathrm{~ms}$, respectively. The CE voltage was in a series set at 15,30 , and $45 \mathrm{~V}$ testing parameters: gas1 and gas2, $50 \mathrm{~Pa}$; curtain gas, $35 \mathrm{~Pa}$; desolvation gas temperature, $500{ }^{\circ} \mathrm{C}$; source temperature, $500{ }^{\circ} \mathrm{C}$; ion spray voltage floating (ISVF), $5000 \mathrm{~V}$ (ESI+) or $-4500 \mathrm{~V}$ (ESI-); declustering potential (DP), $80 \mathrm{~V}$ (ESI+) or $-80 \mathrm{~V}$ (ESI-); collision energy, $30 \pm 15 \mathrm{eV}$.

Identification of Chemical Compounds in Serum. MS/MS data were sent to Progenesis QI for peak picking, alignment, integration, and extraction of the peak intensities. METLIN and HMDB database were used for the first-step identification of compounds in serum. The MS spectra of preidentified compounds (score $>50$, mass error $<10$ ppm, $q$ value $<0.05$, Anova $(p)<0.05)$ were matched against by a manual method to ensure the accuracy of the compounds' identification. A two-tailed Welch's $t$ test with false discovery rate (FDR) correction was used for the statistical analysis of compound differences between control and treatment groups. The significantly perturbed compounds $(q$ value $<0.05$, Anova $(p)<0.05$, max fold change $>3$ ) were considered to be differential compounds that are triggered by arsenic exposure.

Statistical Analysis. Principal components analysis (PCA) and orthogonal partial least-squares discrimination analysis (OPLS-DA) were used to distinguish differences in mouse serum samples after exposure to different concentrations of arsenic. The permutation test was used to verify the reliability of the statistical model. All statistical analyses were performed by SIMCA 14.1 .

\section{ASSOCIATED CONTENT}

\section{(s) Supporting Information}

The Supporting Information is available free of charge at https://pubs.acs.org/doi/10.1021/acsomega.1c04517.

Quality control results of the UPLC-MS/MS test, information of all identified compounds in serum after arsenic exposure, and the results of dentification of inosine, xanthine, xanthosine, and hypoxanthine by MS/ MS experiments with standard chemicals (PDF)

\section{AUTHOR INFORMATION}

\section{Corresponding Authors}

Kun He - National Center for Biomedical Analysis, Beijing 100850,China; Email: hk@proteomics.cn

Na Wang - National Center for Biomedical Analysis, Beijing 100850, China; Phone: 86-10-66930306; Email: nwang@ ncba.ac.cn

\section{Authors}

Nan Jing - National Center for Biomedical Analysis, Beijing

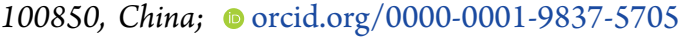

Xinzheng Wang - National Center for Biomedical Analysis, Beijing 100850, China

Xin Yang - National Center for Biomedical Analysis, Beijing 100850, China

Qian Liu - National Center for Biomedical Analysis, Beijing 100850, China

Hongxia Wang - National Center for Biomedical Analysis, Beijing 100850, China; $\odot$ orcid.org/0000-0002-98209261

Fangting Dong - National Center for Biomedical Analysis, Beijing 100850, China

Complete contact information is available at:

https://pubs.acs.org/10.1021/acsomega.1c04517

\section{Notes}

The authors declare no competing financial interest.

\section{ACKNOWLEDGMENTS}

We are grateful to the financial support from the Project of China Postdoctoral Science Foundation (Project no. 2020 M673691) and the National Key Research and Development Program of China (nos. 2017YFC1601101, 2017YFC1601102, and 2017YFC1601104).

\section{REFERENCES}

(1) Dai, L.; Lv, X.; Chen, Z.; Huang, Z.; Li, B.; Xie, Y.; Duan, Y.; Zhao, H.; Wang, Y.; Yu, Q.; Li, S.; Zhou, Y.; Shen, X. Elevated whole 
blood arsenic level is associated with type 2 diabetes in coal-burning areas in Guizhou. Toxicol. Appl. Pharm. 2020, 403, 115135.

(2) Grau-Perez, M.; Navas-Acien, A.; Galan-Chilet, I.; BriongosFiguero, L. S.; Morchon-Simon, D.; Bermudez, J. D.; Crainiceanu, C. M.; Marco, G.; Rentero-Garrido, P.; Garcia-Barrera, T.; Gomez-Ariza, J. L.; Casasnovas, J. A.; Martin-Escudero, J. C.; Redon, J.; Chaves, F. J.; Tellez-Plaza, M. Arsenic exposure, diabetes-related genes and diabetes prevalence in a general population from Spain. Environ. Pollut. 2018, 235, 948-955.

(3) Spratlen, M. J.; Grau-Perez, M.; Umans, J. G.; Yracheta, J.; Best, L. G.; Francesconi, K.; Goessler, W.; Balakrishnan, P.; Cole, S. A.; Gamble, M. V.; Howard, B. V.; Navas-Acien, A. Arsenic, one carbon metabolism and diabetes-related outcomes in the Strong Heart Family Study. Environ. Int. 2018, 121, 728-740.

(4) Sumedha, N. C.; Miltonprabu, S. Retracted: Cardiac mitochondrial oxidative stress and dysfunction induced by arsenic and its amelioration by diallyl trisulphide. Toxicol. Res. 2015, 4, 291301.

(5) Xu, L.; Polya, D. A.; Li, Q.; Mondal, D. Association of low-level inorganic arsenic exposure from rice with age-standardized mortality risk of cardiovascular disease (CVD) in England and Wales. Sci. Total Environ. 2020, 743, 140534.

(6) Yao, X.; Xu, X. S.; Yang, Y.; Zhu, Z.; Zhu, Z.; Tao, F.; Yuan, M. Stratification of population in NHANES 2009-2014 based on exposure pattern of lead, cadmium, mercury, and arsenic and their association with cardiovascular, renal and respiratory outcomes. Environ. Int. 2021, 149, 106410.

(7) Ochoa-Martínez, Á. C.; Ruiz-Vera, T.; Almendarez-Reyna, C. I.; Zarazúa, S.; Carrizales-Yáñez, L.; Pérez-Maldonado, I. N. Impact of arsenic exposure on clinical biomarkers indicative of cardiovascular disease risk in Mexican women. Ecotox. Environ. Safe. 2019, 169, 678686.

(8) Wei, S.; Zhang, H.; Tao, S. A review of Arsenic Exposure and Lung Cancer. Toxicol. Res. 2019, 8, 319-327.

(9) Lamm, S. H.; Boroje, I. J.; Ferdosi, H.; Ahn, J. A review of lowdose arsenic risks and human cancers. Toxicology 2021, 456, 152768.

(10) Cardoso, A. P. F.; Udoh, K. T.; States, J. C. Arsenic-induced changes in miRNA expression in cancer and other diseases. Toxicol. Appl. Pharm. 2020, 409, 115306.

(11) Shao, K.; Zhou, Z.; Xun, P.; Cohen, S. M. Bayesian benchmark dose analysis for inorganic arsenic in drinking water associated with bladder and lung cancer using epidemiological data. Toxicology 2021, $455,152752$.

(12) Zeng, Q.; Zhang, A. Assessing potential mechanisms of arsenicinduced skin lesions and cancers: Human and in vitro evidence. Environ. Pollut. 2020, 260, 113919.

(13) Abdul, K. S. M.; Jayasinghe, S. S.; Chandana, E. P. S.; Jayasumana, C.; Silva, P. M. C. S. Arsenic and human health effects: A review. Environ. Toxicol. Phar. 2015, 40, 828-846.

(14) Yuan, T.; Zhang, H.; Chen, B.; Zhang, H.; Tao, S. Lung cancer risk and inorganic arsenic exposure in drinking water: a dose-response meta-analysis. Toxicol. Res. 2018, 7, 1257-1266.

(15) Yogarajah, N.; Tsai, S. S. H. Detection of trace arsenic in drinking water: challenges and opportunities for microfluidics. Environ. Sci-Wat. Res. 2015, 1, 426-447.

(16) Neil, C. W.; Yang, Y. J.; Jun, Y.-S. Arsenic mobilization and attenuation by mineral-water interactions: implications for managed aquifer recharge. J. Environ. Monitor. 2012, 14, 1772-1788.

(17) Rathi, B. S.; Kumar, P. S. A review on sources, identification and treatment strategies for the removal of toxic Arsenic from water system. J. Hazard. Mater. 2021, 418, 126299.

(18) Thakkar, S.; Dumée, L. F.; Gupta, M.; Singh, B. R.; Yang, W. Nano-Enabled sensors for detection of arsenic in water. Water Res. 2021, 188, 116538.

(19) Li, Y.; Ji, L.; Mi, W.; Xie, S.; Bi, Y. Health risks from groundwater arsenic on residents in northern China coal-rich region. Sci. Total Environ. 2021, 773, 145003.
(20) Hu, Y.; Xiao, T.; Zhang, A. Associations between and risks of trace elements related to skin and liver damage induced by arsenic from coal burning. Ecotox. Environ. Safe. 2021, 208, 111719.

(21) Dhillon, A.; Nair, M.; Kumar, D. Analytical methods for sensing of health hazardous arsenic from biotic and abiotic natural resources. Anal. Methods 2015, 7, 10088-10108.

(22) Wang, Z.; Cui, Z.; Xu, X. Lysosomal membrane response of the earthworm, Eisenia fetida, to arsenic species exposure in OECD soil. RSC Adv. 2016, 6, 23498-23507.

(23) Wang, Z.; Cui, Z. Accumulation, biotransformation, and multibiomarker responses after exposure to arsenic species in the earthworm Eisenia fetida. Toxicol. Res. 2016, 5, 500-510.

(24) Zamora, P. L.; Rockenbauer, A.; Villamena, F. A. Radical Model of Arsenic (III) Toxicity: Theoretical and EPR Spin Trapping Studies. Chem. Res. Toxicol. 2014, 27, 765-774.

(25) Hwang, I. M.; Lee, H. M.; Lee, H.-W.; Jung, J.-H.; Moon, E. W.; Khan, N.; Kim, S. H. Determination of Toxic Elements and Arsenic Species in Salted Foods and Sea Salt by ICP-MS and HPLCICP-MS. ACS Omega 2021, 6, 19427-19434.

(26) Wang, N.-X.; Liu, Y.-Y.; Wei, Z.-B.; Yang, L.-Y.; Miao, A.-J. Waterborne and Dietborne Toxicity of Inorganic Arsenic to the Freshwater Zooplankton Daphnia magna. Environ. Sci. Technol. 2018, 52, 8912-8919.

(27) Flora, S. J. S.; Mittal, M.; Pachauri, V.; Dwivedi, N. A possible mechanism for combined arsenic and fluoride induced cellular and DNA damage in mice. Metallomics 2012, 4, 78-90.

(28) Li, J.; Ma, L.; Wang, X.; Li, D.; Zeng, Q.; Xing, X.; Li, C.; Xie, L.; Chen, L.; Chen, W.; Zhang, A. Modifications of H3K9me2, H3K36me3 and H4K20me2 may be involved in arsenic-induced genetic damage. Toxicol. Res. 2016, 5, 1380-1387.

(29) Tam, L. M.; Price, N. E.; Wang, Y. Molecular Mechanisms of Arsenic-induced Disruption of DNA Repair. Chem. Res. Toxicol. 2020, 33, 709-726.

(30) Laine, V. N.; Verschuuren, M.; Oers, K.; Espín, S.; SánchezVirosta, P.; Eeva, T.; Ruuskanen, S. Does Arsenic Contamination Affect DNA Methylation Patterns in a Wild Bird Population? An Experimental Approach. Environ. Sci. Technol. 2021, 55, 8947-8954.

(31) Hu, X.; Li, H.; Ip, T. K.; Cheung, Y. F.; Koohi-Moghadam, M.; Wang, H.; Yang, X.; Tritton, D. N.; Wang, Y.; Wang, Y.; Wang, R.; Ng, K.; Naranmandura, H.; Tse, E. W.; Sun, H. Arsenic trioxide targets Hsp60, triggering degradation of p53 and surviving. Chem. Sci. 2021, 10893.

(32) Tam, L. M.; Wang, Y. Arsenic Exposure and Compromised Protein Quality Control. Chem. Res. Toxicol. 2020, 33, 1594-1604.

(33) Li, J.; Packianathan, C.; Rossman, T. G.; Rosen, B. P. Nonsynonymous Polymorphisms in the Human AS3MT Arsenic Methylation Gene: Implications for Arsenic Toxicity. Chem. Res. Toxicol. 2017, 30, 1481-1491.

(34) Chen, B.; Lu, X.; Arnold, L. L.; Cohen, S. M.; Le, X. C. Identification of Methylated Dithioarsenicals in the Urine of Rats Fed with Sodium Arsenite. Chem. Res. Toxicol. 2016, 29, 1480-1487.

(35) Henderson, J. F. Purine metabolism and human disease. Clin. Biochem. 1968, 2, 241-252.

(36) Suzuki, S.; Arnold, L. L.; Ohnishi, T.; Cohen, S. M. Effects of Inorganic Arsenic on the Rat and Mouse Urinary Bladder. Toxicol. Sci. 2008, 106, 350-363. 